УДК 330.34:622.276

ФОРМИРОВАНИЕ ЭФФЕКТИВНОЙ СИСТЕМЫ КОНТРОЛЛИНГА

ПРИ РЕСТРУКТУРИЗАЦИИ ВСПОМОГАТЕЛЬНОГО

ПРОИЗВОДСТВА НЕФТЕХИМИЧЕСКОГО ПРЕДПРИЯТИЯ

\title{
FORMATION OF EFFECTIVE SYSTEM OF CONTROLLING WHEN RESTRUCTURING AUXILIARY PRODUCTION OF THE PETROCHEMICAL ENTERPRISE
}

Гайфуллина М.М., Низамова Г.3., Гареева 3.А.

Уфимский государственный нефтяной технический университет, г. Уфа, Российская Федерация

M.M. Gayfullina, G.Z. Nizamova, Z.A. Gareeva

Ufa State Petroleum Technological University, Ufa, Russian Federation

e-mail: marina_makova@list.ru, gulya182004@list.ru, zem07@bk.ru

Аннотация. $\mathrm{B}$ статье предложен методический подход к формированию эффективной системы контроллинга при реструктуризации вспомогательного производства нефтехимического предприятия.

Актуальность научной статьи вызвана тем обстоятельством, что в современных условиях кризиса российским нефтехимическим предприятиям приходится конкурировать с мировыми компаниями, в последнее время значительно изменившимися по масштабам, по внутренней организации и стратегии развития. Эффективным рыночным инструментом, обеспечивающим функционирование предприятий в изменяющихся условиях, является реструктуризация вспомогательных производств.

В работе представлена классификация вспомогательных производств нефтехимического предприятия. Приведены причины необходимости 
проведения

реструктуризации

вспомогательных

производств

нефтехимического предприятия и показана значимость формирования эффективной системы контроллинга при реструктуризации вспомогательного производства нефтехимического предприятия. Представлена классификация вспомогательных производств исходя из характера их назначения.

В статье представлен алгоритм создания системы контроллинга при реструктуризации вспомогательного производства на нефтехимическом предприятии, включающий выполнение нескольких последовательных этапов - от формирование системы стратегических и оперативных целей нефтехимического предприятия, до расчета эффективности внедрения системы контроллинга при реструктуризации вспомогательного производства нефтехимического предприятия. Приведено поэтапное описание предлагаемого механизма.

Представлена система факторов, влияющих на внедрение контроллинга при реструктуризации вспомогательного производства нефтехимического предприятия.

Предложен интегральный подход к оценке эффективности внедрения системы контроллинга при реструктуризации вспомогательного производства нефтехимического предприятия. Предложена шкала оценки эффективности внедрения системы контроллинга при реструктуризации вспомогательного производства нефтехимического предприятия

Проведена апробация предлагаемого подхода на примере нефтехимического предприятия ООО «Газпром нефтехим Салават», оценена экономическая эффективность внедрения системы контроллинга при реструктуризации вспомогательного производства.

Abstract. In article methodical approach to formation of effective system of controlling when restructuring auxiliary production of the petrochemical enterprise is offered. 
The relevance of the scientific article is caused by that circumstance that in modern conditions of crisis the Russian petrochemical enterprises should compete with the world companies, recently considerably changed on scales, on the internal organization and the development strategy. The effective market tool providing functioning of the enterprises in the changing conditions is restructuring of auxiliary productions.

In work classification of auxiliary productions of the petrochemical enterprise is presented. The reasons of need of carrying out restructuring of auxiliary productions of the petrochemical enterprise are given and the importance of formation of effective system of controlling when restructuring auxiliary production of the petrochemical enterprise is shown. Classification of auxiliary productions proceeding from the nature of their appointment is presented.

In article the algorithm of creation of system of controlling when restructuring auxiliary production at the petrochemical enterprise including performance of several consecutive stages - from formation of system of the strategic and operational objectives of the petrochemical enterprise, before calculation of efficiency of introduction of system of controlling when restructuring auxiliary production of the petrochemical enterprise is presented. The stage-by-stage description of the offered mechanism is provided.

The system of the factors influencing introduction of controlling when restructuring auxiliary production of the petrochemical enterprise is presented.

Integrated approach to assessment of efficiency of introduction of system of controlling when restructuring auxiliary production of the petrochemical enterprise is offered. The scale of assessment of efficiency of introduction of system of controlling when restructuring auxiliary production of the petrochemical enterprise is offered

Approbation of the offered approach on the example of the petrochemical enterprise LLC Gazprom neftekhim Salavat is carried out, the economic 
efficiency of introduction of system of controlling when restructuring auxiliary production is estimated.

Ключевые слова: контроллинг, реструктуризация, вспомогательное производство, эффективность, система, нефтехимическое предприятие.

Key words: controlling, restructuring, auxiliary production, efficiency, system, petrochemical enterprise.

\section{Введение}

Нефтехимическая отрасль России играет важную роль в экономике России. Доля химической индустрии в структуре ВВП России в 2015 г. составила около $6 \%$, в структуре экспорта - около 5 \%, в структуре валютной выручки - около $5 \%$; в отрасли сосредоточено почти $7 \%$ основных фондов промышленности $[1 ; 2]$.

Несмотря на наличие всех фундаментальных предпосылок для развития химического комплекта Россия значительно отстает от мировых лидеров [3; 4]. В глобальном нефтехимическом рейтинге Россия по общему выпуску продукции (около 1 \% мирового объема) замыкает первую двадцатку стран, пропустив вперед не только США и Европу, но и Таиланд, Тайвань, Бразилию, Иран и Китай. При этом в России отсутствует производство целого ряда товаров высоких переделов (таких как специальные композиты, добавки). Например, Китай в настоящее время занимает около четверти мирового рынка производства первичных форм пластмасс, Европа - приблизительно 20 \%, а Россия - всего $2 \%$.

Развитие отечественной нефтехимической отрасли промышленности зависит от модернизации процессов производства, сложности переработки нефти, востребованности и конкурентоспособности производимой продукции [5-7]. Одним из механизмов достижения данной цели является реструктуризация ее вспомогательных производств [8]. При этом от 
организации, создания, разработки и своевременного контроля качества процесса реструктуризации вспомогательного производства нефтехимического предприятия зависит не только эффективность систем управления развитием и интеграция нефтехимических процессов, но и обеспечение процессов принятия обоснованных управленческих решений, направленных на стабилизацию финансовой ситуации, сглаживание рисков банкротства, сохранность активов и повышение рыночной стоимости предприятия [9; 10].

К вспомогательным производствам нефтехимического предприятия относятся производственные процессы, создающие необходимые предпосылки для нормального хода основных процессов (например, процессы, направленные на поддержание в работоспособном состоянии средств труда), в отличие от основных процессов, непосредственно направленных на преобразование предмета труда в продукт труда, т.е. на производство характерной для данного нефтехимического предприятия продукции [11].

Вспомогательные производства является составной и важнейшей частью системы обслуживания производственного процесса. При этом в зависимости от характера назначения, вспомогательные производства делятся на две группь:

1) вспомогательные производства производственного назначения необходимы для обеспечения непрерывности технологического процесса основного производства;

2) вспомогательные производства непроизводственного назначения необходимы для обеспечения производства с технической и с социальноэкономической сторон (таблица 1).

Важное значение при проведении процесса реструктуризации вспомогательных производств нефтехимических предприятий имеет формирование эффективной системы контроллинга на предприятии, поскольку организация, постановка, развитие и своевременность 
качественного контроллинга не только определяет эффективность систем управления развитием и интеграции процессов нефтехимии, но и обеспечивает процесс принятия обоснованных управленческих решений в части реструктуризации ее вспомогательных производств.

Таблица 1. Основные вспомогательные службы и подразделения нефтехимического предприятия непрофильного характера

\begin{tabular}{|c|c|c|}
\hline Группа & \multicolumn{2}{|c|}{ Службы и подразделения } \\
\hline \multirow{9}{*}{$\begin{array}{l}\text { Производственного } \\
\text { назначения }\end{array}$} & \multicolumn{2}{|c|}{ 1. Ремонтно-строительные цехи и службы } \\
\hline & \multicolumn{2}{|c|}{$\begin{array}{l}\text { 2. Подразделения по ремонту и обслуживанию } \\
\text { автоматизированных систем управления и контрольно- } \\
\text { измерительных приборов }\end{array}$} \\
\hline & \multicolumn{2}{|c|}{ 3. Энергетические службы, цеха паро- и водоснабжения } \\
\hline & \multicolumn{2}{|c|}{ 4. Подразделения связи } \\
\hline & \multicolumn{2}{|c|}{ 5. Подразделения материально-технического снабжения } \\
\hline & \multicolumn{2}{|c|}{ 6. Транспортные службы } \\
\hline & \multicolumn{2}{|c|}{ 7. Складские хозяйства } \\
\hline & \multicolumn{2}{|c|}{$\begin{array}{l}\text { 8. Производственно-технологические службы } \\
\text { (производственный отдел, отделы главного технолога и } \\
\text { главного механика) }\end{array}$} \\
\hline & \multicolumn{2}{|c|}{$\begin{array}{l}\text { 9. Службы контроля качества (лаборатория технического } \\
\text { контроля) }\end{array}$} \\
\hline \multirow{10}{*}{$\begin{array}{l}\text { Непроизводственного } \\
\text { назначения }\end{array}$} & \multirow{5}{*}{$\begin{array}{l}\text { 1. Обслуживающие } \\
\text { производства }\end{array}$} & 1. Хозяйственный цех \\
\hline & & 2. Финансово-экономические слубы \\
\hline & & 3. Служба охраны \\
\hline & & 4. Жилищно-коммунальное хозяйство \\
\hline & & 5. Промышленная безопасность \\
\hline & \multirow{5}{*}{$\begin{array}{l}\text { 2. Социальная } \\
\text { сфера }\end{array}$} & $\begin{array}{l}\text { 1. Медицинское обслуживание, } \\
\text { физкультура и спорт }\end{array}$ \\
\hline & & $\begin{array}{l}\text { 2. Инструктаж и производственное } \\
\text { обучение }\end{array}$ \\
\hline & & 3. Техника безопасности и охрана труда \\
\hline & & $\begin{array}{l}\text { 4. Обеспечение информацией и } \\
\text { документацией }\end{array}$ \\
\hline & & 5. Культурно-бытовое обслуживание \\
\hline
\end{tabular}




\section{Методика исследования}

Одним из наиболее эффективных методов формирования эффективной системы контроллинга при реструктуризации вспомогательных производств нефтехимического предприятия является поэтапное изменение потоков предприятия (информационных и управляющих), что означает последовательность определенных шагов. Предлагаемый алгоритм создания системы контроллинга и оценки ее эффективности при реструктуризации вспомогательного производства на нефтехимическом предприятии (рисунок 1).

На первом этапе определяются цели по формированию эффективной системы контроллинга при реструктуризации вспомогательного производства нефтехимического предприятия.

Концептуальная схема создания системы контроллинга при реструктуризации вспомогательного производства на нефтехимическом предприятии ориентирована на установление контроля за достижением целей (как стратегических так и тактических). Возможен следующий перечень целей при формировании эффективной системы контроллинга при реструктуризации вспомогательного производства нефотехимического предприятия.

1. Повышение конкурентоспособности и устойчивости предприятия [12-15].

2. Сокращение времени, необходимого для принятия обоснованных тактических и стратегических решений [16].

3. Улучшение качества решений.

4. Сокращение запасов на предприятии.

5. Разработка обоснованных критериев оценки эффективности подразделений и специалистов [17].

6. 6 .Снижение уровня затрат и транзакционных издержек [18].

7. Обоснование стоимости каждого отдельного продукта.

8. Распределение затрат на предприятии. 
9. Упрощение взаимодействия между бизнес-единицами.

10. Снижение рисков в деятельности предприятия [19; 20; 21].

11. Повышение рыночной стоимости предприятия [22].

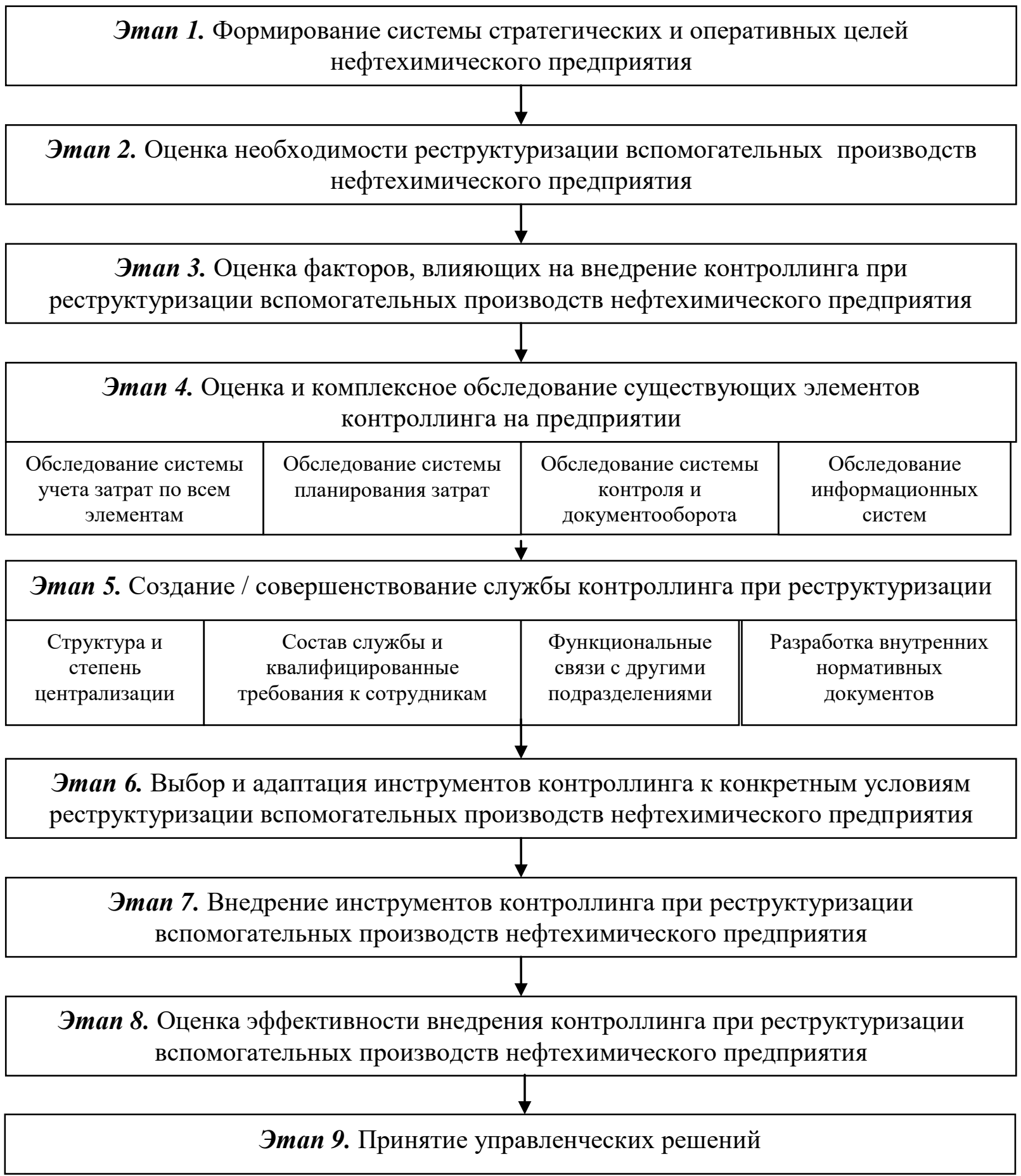

Рисунок 1. Алгоритм создания системы контроллинга при реструктуризации вспомогательного производства на нефтехимическом предприятии 
На втором этапе оценивается необходимость реструктуризации вспомогательных производств нефтехимического предприятия.

В качестве причин, обуславливающих проведение реструктуризацчии вспомогательного производства, можно выделить следующие:

1) уменьшение затрат по содержанию вспомогательных объектов в доле накладных расходов, что приведет к уменьшению себестоимости производимой продукции;

2) стимулирование повышения прозрачности управления и экономики предприятия;

3) приведение оридической и организационно-функциональной структуры компании к общепринятой модели, более понятной инвесторам [23];

4) увеличение производительности труда;

5) стимулирование более полного использования производственных мощностей подразделений;

На третьем этапе производится оценка факторов, влияющих на внедрение контроллинга при реструктуризации вспомогательных производств нефтехимического предприятия.

Система факторов, влияющих на внедрение контроллинга при реструктуризации вспомогательного производства нефтехимического предприятия, приведена в таблице 2.

Для оценки влияния различных факторов на внедрение контроллинга при реструктуризации вспомогательного производства нефтехимического предприятия предлагается использовать метод экспертных оценок. В данном случае можно определить как основные положительные факторы, т.е. те факторы, которые будут способствовать внедрению контроллинга, так и основные негативные факторы, которые будут препятствовать внедрению контроллинга на предприятии. 
Таблица 2. Система факторов, влияющих на внедрение контроллинга при реструктуризации вспомогательного производства нефтехимического предприятия

\begin{tabular}{|c|c|}
\hline Группа факторов & Факторы \\
\hline \multirow{5}{*}{$\begin{array}{l}\text { 1. Финансово- } \\
\text { экономические } \\
\text { факторы }\end{array}$} & 1.1 Общее финансовое состояние предприятия \\
\hline & 1.2. Динамика чистой прибыли предприятия \\
\hline & 1.3 Наличие свободных денежных ресурсов \\
\hline & 1.4 Динамика величины стоимости предприятия \\
\hline & 1.5 Продолжительность существования предприятия на рынке \\
\hline \multirow{5}{*}{$\begin{array}{l}\text { 2. Социальные } \\
\text { факторы }\end{array}$} & 2.1 Уровень квалификации кадров \\
\hline & 2.2 Производительность труда \\
\hline & 2.2 Отлаженность связей между подразделениями \\
\hline & 2.4 Степень децентрализации предприятия \\
\hline & 2.5 Уровень сопротивления нововведениям \\
\hline \multirow{4}{*}{$\begin{array}{l}\text { 3. Инфраструктурные } \\
\text { факторы }\end{array}$} & 3.1 Развитие информационной базы на предприятии \\
\hline & 3.2 Уровень автоматизации системы управления \\
\hline & $\begin{array}{l}3.3 \text { Наличие нормативно-правовой и документальной базы } \\
\text { контроллинга }\end{array}$ \\
\hline & 3.4 Наличие системы управленческого учета \\
\hline
\end{tabular}

На четвертом этапе оцениваются и изучаются отдельные элементы контроллинга, уже существующие в рамках управления предприятием. Проводится оценка существующих элементов контроллинга: проверяется система планирования, учета и контроля затрат, изучается информационная система.

Пятым этапом является создание или совершенствование службы контроллинга в связи с реструктуризацией вспомогательного производства нефтехимического предприятия.

Система контроллинга на предприятии выполняет аналитическую функцию, обеспечивая оперативной информацией об уровне и динамике затрат, необходимых для анализа и прогнозирования финансовоэкономического положения предприятия, а также позволяет проводить экономическую экспертизу управленческих решений, связанных с затратами и прибылью. 
Шестой эman состоит в отборе и адаптации инструментов контроллинга к конкретным условиям предприятия.

Седьмой этап предусматривает внедрение инструментов контроллинга при реструктуризации вспомогательных производств нефтехимического предприятия.

На восьмом этапе осуществляется оценка эффективности системы контроллинга при реструктуризации вспомогательного производства нефтехимического предприятия.

На девятом этапе принимаются управленческие решения по результатам внедрения системы контроллинга при реструктуризации вспомогательного производства нефтехимического предприятия и оценки эффективности внедрения контроллинга.

Нами предлагается для оценки экономической эффективности внедрения системы контроллинга при реструктуризации вспомогательного производства нефтехимического предприятия рассчитывать интегральный показатель эффективности внедрения контроллинга.

Интегральный показатель эффективности внедрения системь контроллинга при реструктуризации вспомогательного производства нефтехимического предприятия предлагается оценивать по формуле среднеарифметической взвешенной:

$$
I=\sum_{i=1}^{n} \ni i * k_{i},
$$

где $Э_{\mathrm{i}}-$ значение i-го критерия эффективности внедрения системы контроллинга;

$\mathrm{k}_{\mathrm{i}}$ - весовой коэффициент значимости i-го критерия.

В качестве критериев эффективности внедрения системь контроллинга при реструктуризации вспомогательного производства нефтехимического предприятия предлагаются следующие показатели. 
1. Индекс изменения рентабельности производства - характеризует степень изменения рентабельности предприятия при реструктуризации вспомогательного производства и внедрении механизма контроллинга:

$$
\Im_{1}=\frac{P_{\kappa}-P_{\partial}}{P_{\partial}} * 100,
$$

где Рк - рентабельность производства после реструктуризации вспомогательного производства и внедрении механизма контроллинга;

Рд - рентабельность производства до реструктуризации вспомогательного производства и внедрении механизма контроллинга.

Рентабельность производства определяется:

$$
P=\frac{\Pi p n}{C} * 100=\frac{B P-C}{C} * 100,
$$

где Прп - прибыль от реализации продукции;

ВР - выручка от реализации продукции;

$\mathrm{C}$ - себестоимость реализованной продукции (включая коммерческие и управленческие расходы).

2. Индекс изменения рентабельности активов - характеризует степень изменения чистой рентабельности активов при реструктуризации вспомогательного производства и внедрении механизма контроллинга:

$$
\ni_{2}=\frac{P A_{\kappa}-P A_{\partial}}{P A_{\partial}} * 100,
$$

где РАк - чистая рентабельность активов после реструктуризации вспомогательного производства и внедрении механизма контроллинга;

РАд - чистая рентабельность активов до реструктуризации вспомогательного производства и внедрении механизма контроллинга.

Рентабельность активов определяется:

$$
P A=\frac{\text { ЧП }}{A} * 100,
$$

где ЧП - чистая прибыль предприятия;

А - стоимость активов нефтехимического предприятия 
3. Индекс изменения рыночной стоимости предприятия характеризует степень изменения рыночной стоимости нефтехимического предприятия при реструктуризации вспомогательного производства и внедрении механизма контроллинга:

$$
\ni_{3}=\frac{C_{\kappa}-C_{\partial}}{C_{\partial}} * 100
$$

где Ск - рыночная стоимость нефтехимического предприятия после реструктуризации вспомогательного производства и внедрении механизма контроллинга;

Сд - рыночная стоимость нефтехимического предприятия до реструктуризации вспомогательного производства и внедрении механизма контроллинга.

4. Индекс изменения активов предприятия - характеризует степень изменения величины активов нефтехимического предприятия при реструктуризации вспомогательного производства и внедрении механизма контроллинга:

$$
\Im_{4}=\frac{A_{\kappa}-A_{\partial}}{A_{\partial}} * 100
$$

где Ак - стоимость активов нефтехимического предприятия после реструктуризации вспомогательного производства и внедрении механизма контроллинга;

Ад - стоимость активов нефтехимического предприятия до реструктуризации вспомогательного производства и внедрении механизма контроллинга.

Стоимость активов нефтехимического предприятия после реструктуризации вспомогательного производства и внедрении механизма контроллинга определяется:

$$
A \kappa=A \partial-A л+A в,
$$

где Ал - величина ликвидированных активов в процессе реструктуризации вспомогательного производства и внедрении механизма контроллинга; 
Ав - величина вновь введенных активов за период проведения реструктуризации вспомогательного производства и внедрении механизма контроллинга.

5. Индекс изменения платежеспособности - характеризует степень изменения платежеспособности нефтехимического предприятия при реструктуризации вспомогательного производства и внедрении механизма контроллинга:

$$
\ni_{5}=\frac{\Pi_{\partial}-\Pi_{\kappa}}{\Pi_{\partial}} * 100,
$$

где Пк - степень платежеспособности нефтехимического предприятия после реструктуризации вспомогательного производства и внедрении механизма контроллинга;

Пд - степень платежеспособности нефтехимического предприятия до реструктуризации вспомогательного производства и внедрении механизма контроллинга.

Степень платежеспособности характеризует, сколько месяцев требуется предприятию для расчета по всем долгосрочным и краткосрочным обязательствам при сохранении сложившегося уровня выручки в гипотетическом случае, если не осуществлять другие платежи:

$$
\Pi=\frac{Д O+K O}{B P_{M}} * 100,
$$

где ДО - долгосрочные обязательства нефтехимического предприятия;

КО - долгосрочные обязательства нефтехимического предприятия;

ВРм - среднемесячная прибыль нефтехимического предприятия.

Положительная динамика данного показателя - это его снижение.

Весовые коэффициенты значимости критериев эффективности внедрения системы контроллинга $\left(\mathrm{k}_{\mathrm{i}}\right)$ предлагается находить одним из наиболее распространенных экспертных методов - методом попароного сравнения. 
По результатам расчета интегрального показателя эффективности внедрения системы контроллинга при реструктуризации вспомогательного производства нефтехимического предприятия оценивается степень эффективности внедрения системы контроллинга (таблица 3).

Таблица 3. Шкала оценки эффективности внедрения системы контроллинга при реструктуризации вспомогательного производства нефтехимического предприятия

\begin{tabular}{|c|c|}
\hline Интегральный показатель эффективности (I), \% & Степень эффективности \\
\hline $\mathrm{I} \geq 120 \%$ & высоко эффективная \\
\hline $100 \% \leq \mathrm{I}<120 \%$ & умеренно эффективная \\
\hline $75 \% \leq \mathrm{I}<100 \%$ & неэффективная \\
\hline $\mathrm{I}<75 \%$ & неудовлетворительная \\
\hline
\end{tabular}

\section{Апробация методики}

Апробация предлагаемой методики оценки экономической эффективности внедрения системы контроллинга при реструктуризации вспомогательного производства нефтехимического предприятия проведена на примере ООО «Газпром нефтехим Салават».

В 2016 г. осуществлена реструктуризации вспомогательного производства нефтехимического предприятия, в частности возвращено в структуру предприятия и интегрировано в основной производственный цикл дочернее предприятие ООО «Политар». ООО «Политар» является одним из крупнейших производителей промышленной упаковки. Ассортимент производимой продукции ООО «Политар» представлен широким спектром полипропиленовых мешков, мягких контейнеров (БигБегов), полиэтиленовой пленки, в том числе и термоусадочной пленки, а также товарами народного потребления из пластика, которые находят сбыт на рынках Республики Башкортостан, регионов России и СНГ. 
При реструктуризации вспомогательного производства были усовершенствованы механизмы контроллинга, в результате показатели компании улучшились.

В таблице 4 представлены результаты оценки экономической эффективности внедрения системы контроллинга при реструктуризации вспомогательного производства на нефтехимическом предприятии ООО «Газпром нефтехим Салават».

Таблица 4. Оценка экономической эффективности внедрения системы контроллинга при реструктуризации вспомогательного производства нефтехимического предприятия ООО «Газпром нефтехим Салават»

\begin{tabular}{|l|c|c|c|}
\hline \multicolumn{1}{|c|}{ Показатель } & $\begin{array}{c}\text { Значение } \\
\text { Эі, \% }\end{array}$ & Вес & $\begin{array}{c}\text { Средневзвешенное } \\
\text { значение Эі }\end{array}$ \\
\hline $\begin{array}{l}\text { Индекс изменения рентабельности } \\
\text { производства (Э1) }\end{array}$ & 106,8 & 0,254 & 27,1 \\
\hline $\begin{array}{l}\text { Индекс изменения рентабельности } \\
\text { активов (Э2) }\end{array}$ & 110,9 & 0,191 & 21,1 \\
\hline $\begin{array}{l}\text { Индекс изменения рыночной стоимости } \\
\text { предприятия (Э3) }\end{array}$ & 108,0 & 0,373 & 40,3 \\
\hline $\begin{array}{l}\text { Индекс изменения активов предприятия } \\
\text { (Э4) }\end{array}$ & 100,3 & 0,058 & 5,8 \\
\hline $\begin{array}{l}\text { Индекс изменения платежеспособности } \\
\text { (Э5) }\end{array}$ & 99,93 & 0,124 & 12,4 \\
\hline $\begin{array}{l}\text { Интегральный показатель эффективности } \\
\text { (І) }\end{array}$ & - & 1,000 & 106,8 \\
\hline
\end{tabular}

Так как I = 106,8 (находится в границе $100 \% \leq \mathrm{I}<120 \%$ ), то можно констатировать умеренную эффективность внедрения системы контроллинга при реструктуризации вспомогательного производства.

\section{Выводы}

1. Реструктуризация является одним из механизмов повышения экономической эффективности производства в нефтехимической промышленности. Применение системы контроллинга при реструктуризации вспомогательного производства нефтехимического 
предприятия позволяет повысить эффективность деятельности предприятия.

2. Предложенная методика оценки экономической эффективности внедрения системы контроллинга при реструктуризации вспомогательного производства нефтехимического предприятия позволяет:

- оценить эффективность внедрения системы контроллинга при реструктуризации вспомогательного производства нефтехимического предприятия;

- отследить динамику интегрального показателя эффективности внедрения системы контроллинга при реструктуризации вспомогательного производства нефтехимического предприятия в течение определенного периода;

- выявить причины неэффективности внедрения системы контроллинга при реструктуризации вспомогательного производства нефтехимического предприятия.

3. Использование формализованного подхода к оценке позволяет автоматизировать расчет показателя эффективности внедрения системы контроллинга при реструктуризации вспомогательного производства нефтехимического предприятия в рамках информационной системы предприятия.

\section{Список используемых источников}

1. Гайфуллина М.M., Низамова Г.3. Перспективы развития химической отрасли Российской Федерации // Вестник экономики и менеджмента. 2017. № 4. С. 5-11.

2. Burenina I., Evtushenko E., Kotov D., Battalova A.,Gaifullina M., Gamilova D. Integral Assessment of the Development of Russia's Chemical Industry // Journal of Environmental Management and Tourism. 2017. Vol. 8, No. 5. P. 1075-1085. 
3. Буренина И.В., Бирюкова В.В., Котов Д.В., Гайфуллина М.М., Гамилова Д.А. Стратегический анализ и оценка потенциала развития производства резиновых и пластмассовых изделий в Республике Башкортостан // Интернет-журнал «Науковедение». 2016. Т. 8. № 1 (32). C. 31. URL: https://naukovedenie.ru/PDF/33EVN116.pdf. (дата обращения: 01.04.2018).

4. Буренина И.В., Евтушенко Е.В., Котов Д.В., Батталова А.А., Бирюкова В.В., Гайфуллина М.М., Гамилова Д.А., Сайфуллина С.Ф., Тасмуханова А.Е., Захарова И.М. Формирование стратегических приоритетов развития топливно-энергетического и строительного комплексов Республики Башкортостан: теория и практика. Уфа: Изд-во УГНТУ, 2016. $390 \mathrm{c.}$

5. Гайфуллина М.M., Маков В.M. Оценка развития нефтеперерабатывающего сектора Российской Федерации // Нефтегазовое дело. 2016. Т. 14. № 4. С. 208-214.

6. Маков В.M. Анализ состояния нефтеперерабатывающей промышленности Российской Федерации // Вестник экономики и менеджмента. 2017. № 2 (8). С. 58-67.

7. Макова М.М., Маков В.М. Тенденции инновационного развития нефтегазового комплекса России // Химическая техника. 2010.№ 9. C. 30-32.

8. Гайфуллина М.М., Маков В.М., Павлова Ю.А. Методический подход к оценке эффективности реструктуризации нефтяной компании // Экономический анализ: теория и практика. 2018. Т. 17. № 2. С. 324-339.

9. Gajfullina M.M., Nizamova G.Z., Musina D.R., Alexandrova O.A. Formation of Strategy of Effective Management of Fixed Production Assets of Oil Company // Advances in Economics, Business and Management Research. 2017, Vol. 38. P. 185-190. 
10. Гайфуллина М.M., Низамова Г.3. Оценка стоимости и эффективности использования собственного капитала нефтяных компаний Российской Федерации // Электронный научный журнал «Нефтегазовое дело». $2017 . \quad$ № $5 . \quad$ C. $206-226 . \quad$ URL: http://ogbus.ru/issues/5_2017/ogbus_5_2017_p206-226_GayfullinaMM_ru.pdf.

11. Буренина И.В., Евтушенко Е.В., Котов Д.В., Гайфуллина М.М., Земцова В.Д. Основы производственного менеджмента на предприятиях нефтеперерабатывающей и нефтехимической промышленности: учебное пособие / Допущено УМО по образованию в области производственного менеджмента в качестве учебного пособия для студентов высших учебных заведений, обучающихся по направлению подготовки 080200 «Менеджмент». Уфа: Изд-во УГНТУ, 2016. 180 с.

12. Гайфуллина М.М. Интегральный подход к оценке устойчивого развития предприятия // Вестник ВЭГУ. 2013. № 6. С. 27-35.

13. Гайфуллина М.М., Низамова Г.3. Проблемы и перспективы устойчивого развития стран-членов ОПЕК // Электронный научный журнал «Нефтегазовое дело». 2015. № 2. С. 339-356. URL: http://ogbus.ru/issues/2_2015/ogbus_2_2015_p339-356_GayfullinaMM_ru.pdf.

14. Гайфуллина М.М., Земцова В.Д., Ибрагимова Н.В. Методический подход к оценке экономической устойчивости нефтяной компании // Интеллект. Инновации. Инвестиции. 2017. № 8. С. 20-24.

15. Сафина А.А., Гайфуллина М.М. Оценка устойчивого развития малых нефтяных компаний // Электронный научный журнал «Нефтегазовое дело». 2015. № 1. С. 364-381. URL: http://ogbus.ru/issues/1_2015/ogbus_1_2015_p364-381_Safina_ru.pdf.

16. Хуснуллина Г.З., Макова М.М. Повышение эффективности инвестиционной деятельности предприятий комплекса. Уфа: Изд-во УГНТУ, 2007. $161 \mathrm{c.}$ 
17. Хамитова Э.Ф., Гайфуллина М.М. Оценка конкурентоспособности молодых специалистов нефтяных компаний // Нефтегазовое дело. 2014. Т. 12. № 1. С. 190-195.

18. Валиахметова А.Ю., Низамова Г.З. Управление затратами // 63-я научно-техническая конференция студентов, аспирантов и молодых ученых УГНТУ: сборник материалов конференции. Уфа: Изд-во УГНТУ, 2012. C. 226-227.

19. Гайфуллина М.М., Маков В.М. Оценка рисков при найме персонала (на примере предприятий нефтегазового профиля) // Экономика и менеджмент систем управления. 2017. Т. 24. № 2.1. С. 121-127.

20. Маков В.М. Риск-менеджмент на нефтеперерабатывающем предприятии // Нефтегазопереработка-2016: Международная научнопрактическая конференция (Уфа, 24 мая 2016 г.): материалы конференции. Уфа: Изд-во ГУП ИНХП РБ, 2016. С. 14-15.

21. Чеботарев Е.И., Низамова Г.З. Взаимосвязь рисков и форм финансирования инвестиционных проектов // Вестник экономки и менеджмента. 2015. № 1 (1). С. 25-29.

22. Низамова Г.3., Гайфуллина М.М., Суюндукова А.А. Оценка рыночной стоимости нефтехимического предприятия // Евразийский юридический журнал. 2017. № 12 (115). С. 381-383.

23. Низамова Г.З., Чеботарев Е.И. Формирование оптимальной структуры источников финансирования инвестиционных проектов в нефтегазовой отрасли // Интернет-журнал «Науковедение». 2016. Т. 8. № 2 (33).

\section{References}

1. Gajfullina M.M., Nizamova G.Z. Perspektivy razvitija himicheskoj otrasli Rossijskoj Federacii [Prospects of Development of Chemical Branch of the Russian Federation]. Vestnik ekonomiki i menedzhmenta - Bulletin of Economics and Management, 2017, No. 4 (10). pp. 5-11. [in Russian]. 
2. Burenina I., Evtushenko E., Kotov D., Battalova A.,Gaifullina M., Gamilova D. Integral Assessment of the Development of Russia's Chemical Industry. Journal of Environmental Management and Tourism, 2017, Vol. 8, No. 5, pp. 1075-1085.

3. Burenina I.V., Birjukova V.V., Kotov D.V., Gajfullina M.M., Gamilova D.A. Strategicheskij analiz i ocenka potenciala razvitija proizvodstva rezinovyh i plastmassovyh izdelij v Respublike Bashkortostan [The Strategic Analysis and Assessment of Potential of Development of Production of Rubber and Plastic Products in the Republic of Bashkortostan]. Internet-zhurnal «Naukovedenie» - Internet Journal «Naukovedenie», 2016, Vol. 8, No. 1 (32). [in Russian].

4. Burenina I.V., Evtushenko E.V., Kotov D.V., Battalova A.A., Birjukova V.V., Gajfullina M.M., Gamilova D.A., Sajfullina S.F., Tasmuhanova A.E., Zaharova I.M. Formirovanie strategicheskih prioritetov razvitija toplivno-jenergeticheskogo i stroitel'nogo kompleksov Respubliki Bashkortostan: teorija i praktika: monografija [Formation of Strategic Priorities of Development of Fuel and Energy and Construction Complexes of the Republic of Bashkortostan: Theory and Practice]. Ufa, USPTU Publ., 2016. 390 p. [in Russian].

5. Gaifullina M.M., Makov V.M. Otsenka razvitiya neftepererabatyvayushchego sektora Rossiiskoi Federatsii [Assessment of Development of Oil Processing Sector of the Russian Federation]. Neftegazovoe delo-Petroleum Engineering, 2016, T. 14, No. 4, pp. 208-214. [in Russian].

6. Makov V.M. Analiz sostoyaniya neftepererabatyvayushchei promyshlennosti Rossiiskoi Federatsii [Analysis of the State of the Oil Refining Industry of the Russian Federation]. Vestnik ekonomiki $i$ menedzhmenta Bulletin of Economics and Management, 2017, No. 2 (8), pp. 58-67. [in Russian]. 
7. Makova M.M., Makov V.M. Tendencii innovacionnogo razvitija neftegazovogo kompleksa Rossii [Tendencies of Innovative Development of an Oil and Gas Complex of Russia]. Himicheskaya tekhnika - Chemical Equipment, 2010, No. 9, pp. 30-32. [in Russian].

8. Gajfullina M.M., Makov V.M., Pavlova Ju.A. Metodicheskij podhod k ocenke jeffektivnosti restrukturizacii neftjanoj kompanii [Methodological Approach to Assessing the Effectiveness of the restructuring of the Oil Company]. Jekonomicheskij analiz: teorija i praktika - Economic Analysis: Theory and Practice. 2018, Vol. 17, Issue 2, pp. 324-339.

9. Gaifullina M.M., Nizamova G.Z., Musina D.R., Alexandrova O.A. Formation of Strategy of Effective Management of Fixed Production Assets of Oil Company. Advances in Economics, Business and Management Research, 2017, Vol. 38, pp. 185-190.

10. Gajfullina M.M., Nizamova G.Z. Ocenka stoimosti i jeffektivnosti ispol'zovanija sobstvennogo kapitala neftjanyh kompanij Rossijskoj Federacii [Estimation of Cost and Efficiency of Use of Equity of the Oil Companies of the Russian Federation]. Neftegazovoe delo - Oil and Gas Business, 2017, No. 5, pp. 206-226. [in Russian]. Available at: URL: http://ogbus.ru/issues/5_2017/ogbus_5_2017_p206-226_GayfullinaMM_ru.pdf. (accessed 01.04.2018).

11. Burenina I.V., Evtushenko E.V., Kotov D.V., Gajfullina M.M., Zemcova V.D. Osnovy proizvodstvennogo menedzhmenta na predprijatijah neftepererabatyvajushhej i neftehimicheskoj promyshlennosti: uchebnoe posobie [Bases of Production Management at the Enterprises of the Oil-Processing and Petrochemical Industry: Manual]. Ufa, USPTU Publ., 2016. 180 p. [in Russian].

12. Gaifullina M.M. Integral'nyi podkhod k otsenke ustoichivogo razvitiya predpriyatiya [Integral Approach to the Assessment of Sustainable Enterprise Development]. Vestnik VEGU - Herald of VEGU, 2013, No. 6, pp. 27-35. [in Russian]. 
13. Gaifullina M.M., Nizamova G.Z. Problemy i perspektivy ustoichivogo razvitiya stran-chlenov OPEK [Problems and Prospects of Sustainable Economic Development of OPEC Countries]. Elektronnyi nauchnyi zhurnal «Neftegazovoe delo»-Electronic Scientific Journal «Oil and Gas Businesss», 2015, No. 2, pp. 339-356. URL: http://ogbus.ru/issues/2_2015/ ogbus_2_2015_p339-356_GayfullinaMM_ru.pdf. [in Russian].

14. Gajfullina M.M., Zemcova V.D., Ibragimova N.V. Metodicheskij podhod k ocenke jekonomicheskoj ustojchivosti neftjanoj kompanii [Methodical Approach to Assessment of Economic Stability of the Oil Company]. Intellekt. Innovatsii. Investitsii - Intelligence. Innovations. Investments, 2017, No. 8, pp. 20-24. [in Russian].

15. Safina A.A., Gajfullina M.M. Ocenka ustojchivogo razvitija malyh neftjanyh kompanij [Score of Sustainable Development of Small Oil Companies]. Neftegazovoe delo - Oil and Gas Business, 2015, No. 1, pp. 364381. [in Russian]. Available at: URL: http://ogbus_1_2015_p364381_SafinaAA_ru.pdf. (accessed 01.04.2018).

16. Khusnullina G.Z., Makova M.M. Povyshenie effektivnosti investitsionnoi deyatel'nosti predpriyatii [Increase of Efficiency of Investment Activity of Enterprises]. Ufa, UGNTU Publ., 2007. [in Russian].

17. Hamitova Je.F., Gajfullina M.M. Ocenka konkurentosposobnosti molodyh specialistov neftjanyh kompanij [Assessment of Competitiveness of Young Specialists of the Oil Companies]. Neftegazovoe delo - Petroleum Engineering, 2014, Vol. 12, No. 1, pp. 190-195. [in Russian].

18. Valiakhmetova A.Yu., Nizamova G.Z. Upravlenie zatratami [Cost Management]. Sbornik materialov 63 nauchno-tekhnicheskoi konferentsii studentov, aspirantov i molodykh uchenykh UGNTU [Collection of Materials of 63 Scientific and Technical Conference of Students, Graduate Students and Young Scientists of UGNTU]. Ufa, UGNTU Publ., 2012, pp. 226-227. [in Russian]. 
19. Gajfullina M.M., Makov V.M. Ocenka riskov pri najme personala (na primere predprijatij neftegazovogo profilja) [Assessment of Risks When Hiring Personnel (on the Example of the Enterprises of an Oil and Gas Profile)]. Jekonomika i menedzhment sistem upravlenija - Economy and Management of Control Systems, 2014, Vol. 24, No. 2.1, pp. 121-127. [in Russian].

20. Makov V.M. Risk-menedzhment na neftepererabatyvajushhem predprijatii [Risk-Management at the Oil Processing Enterprise]. Materialy mezhdunarodnoi nauchno-prakticheskoi konferencii «Neftegazopererabotka2016» (Ufa, 24 maja 2016 g.) [Materials of the International Scientific and Practical conference «Oil and Gas Processing - 2016» (Ufa, May, 24, 2016)]. Ufa, GUP INHP RB Publ., 2016, pp. 14-15. [in Russian].

21. Chebotarev E.I., Nizamova G.Z. Vzaimosvyaz' riskov i form finansirovaniya investitsionnykh proektov [Interrelation of Risks and Forms of Financing Investment Projects]. Vestnik ekonomki i menedzhmenta - Bulletin of Economics and Management, 2015, No. 1 (1), pp. 25-29. [in Russian].

22. Nizamova G.Z., Gajfullina M.M., Sujundukova A.A. Ocenka rynochnoj stoimosti neftehimicheskogo predprijatija [Assessment of Market Value of the Petrochemical Enterprise]. Evrazijskij juridicheskij zhurnal - Euroasian Low Journal, 2017, No. 12 (115), pp. 381-383. [in Russian].

23. Nizamova G.Z., Chebotarev E.I. Formirovanie optimal'noi struktury istochnikov finansirovaniya investitsionnykh proektov $\mathrm{v}$ neftegazovoi otrasli [Formation of the Optimal Structure of Financing Sources for Investment Projects in the Oil and Gas Industry]. Internet-zhurnal «Naukovedenie»Internet Journal «Naukovedenie», 2016, Vol. 8, No. 2 (33). [in Russian]. 


\section{Сведения об авторах}

\section{About the authors}

Гайфуллина М.М., канд. экон. наук, доцент кафедры экономики и управления на предприятии нефтяной и газовой промышленности, ФГБОУ ВО «УГНТУ», г. Уфа, Российская Федерация

M.M. Gayfullina, Candidate of Economics, Associate Professor of Economics and Management of Oil and Gas Industry Department, FSBEI HE «USPTU», Ufa, Russian Federation

e-mail: marina_makova@list.ru

Низамова Г.З., канд. экон. наук, доцент кафедры экономики и управления на предприятии нефтяной и газовой промышленности, ФГБОУ ВО «УГНТУ», г. Уфа, Российская Федерация

G.Z. Nizamova, Candidate of Economics, Associate Professor of Economics and Management of Oil and Gas Industry Department, FSBEI HE «USPTU», Ufa, Russian Federation

e-mail: gulya182004@list.ru

Гареева 3.А., канд. экон. наук, доцент кафедры экономики и управления на предприятии нефтяной и газовой промышленности, ФГБОУ ВО «УГНТУ», г. Уфа, Российская Федерация

Z.A. Gareeva, Candidate of Economics, Associate Professor of Economics and Management of Oil and Gas Industry Department, FSBEI HE «USPTU», Ufa, Russian Federation

e-mail: zem07@bk.ru 